\title{
Semen Does Not Cause Additional Risk for SARS-CoV-2 Transmission during Sexual Contact
}

\author{
Bircan Kayaaslan $^{a}$ Gulay Korukluoglu ${ }^{b}$ Imran Hasanoglua ${ }^{a}$ Ayse Kaya Kalem ${ }^{a}$

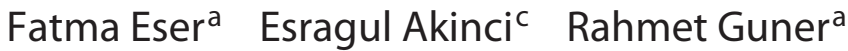 \\ a Infectious Disease and Clinical Microbiology, Ankara Yildirim Beyazit University, Ankara City Hospital, \\ Ankara, Turkey; ${ }^{b}$ Clinical Microbiology, Virology, National Virology Laboratory, Turkish Public Health \\ Institution, Ankara, Turkey; ' Infectious Disease and Clinical Microbiology, University of Health Sciences, \\ Ankara City Hospital, Ankara, Turkey
}

Dear Editor,

We read the letter to the editor by $\mathrm{V}$. Wiwanitkit with the title "SARS-CoV-2 in semen" [1]. The author emphasizes that even if semen has a very low possibility for transmission of the virus, the disease can be transmitted by the respiratory route due to the very close contact between partners. Actually, we think the same as the author. Transmission with respiratory secretions during sexual contact poses a much greater risk than the transmission through semen $[2,3]$. We think that even if severe acute respiratory syndrome coronavirus-2 (SARS-CoV-2) is detected in a patient's semen sample, it is quite difficult to say that the transmission between partners has solely been through semen. As the risk of transmission with respiratory secretion is clearly defined from the beginning of the pandemic, we did not have a need to emphasize this point. In our study, we only aimed to investigate the role of semen in disease transmission. The risk of respiratory contact or other risky behaviors that are revealed during sexual activity was not mentioned. Our study argues that there is probably no additional transmission risk via semen. The available data also support our study that SARS$\mathrm{CoV}-2$ is not a sexually transmitted virus [4-8]. However, sexual contact carries a high risk in terms of SARS-CoV-2 transmission between partners through the respiratory secretions, not semen.

\section{Conflict of Interest Statement}

There is no conflict of interest.

\section{Author Contributions}

All authors searched the literature and argued the text. Bircan Kayaaslan wrote the letter. All authors read and accepted the final version. karger@karger.com

www.karger.com/uin

Karger"
(C) 2020 S. Karger AG, Basel
Bircan Kayaaslan

Infectious Disease and Clinical Microbiology

Ankara Yildirim Beyazit University, Ankara City Hospital

Bilkent Street No. 1, TR-06800 Ankara (Turkey)

drbican@gmail.com 


\section{References}

1 Wiwanitkit V. SARS-CoV-2 in semen. Urol Int. 2020. DOI: 10.1159/000511616.

2 World Health Organization. Transmission of SARS-CoV-2: implications for infection prevention precautions. 2020. Available from: https://www.who.int/news-room/commentaries/detail/transmission-of-sars-cov-2-implications-for-infection-prevention-precautions. Accessed 3 September 2020.

3 Liu J, Liao X, Qian S, Yuan J, Wang F, Liu Y, et al. Community Transmission of Severe Acute Respiratory Syndrome Coronavirus 2, Shenzhen, China, 2020. Emerg Infect Dis. 2020 Jun;26(6):1320-3.
4 Pan F, Xiao X, Guo J, Song Y, Li H, Patel DP, et al. No evidence of severe acute respiratory syndrome-coronavirus 2 in semen of males recovering from coronavirus disease 2019. Fertil Steril. 2020 Jun;113(6):1135-9.

5 Li D, Jin M, Bao P, Zhao W, Zhang S. Clinical characteristics and results of 21 semen tests among men with coronavirus disease 2019. JAMA Netw Open. Published 22 online 2020 May 1;3(5):e208292. doi: https:// doi.org/10.1001/jamanetworkopen.2020. 8292.

6 Guo L, Zhao S, Li W, Wang Y, Li L, Jiang S, et al. Absence of SARS-CoV-2 in semen of a CO-
VID-19 patient cohort [published online ahead of print, 2020 Jun 29]. Andrology. 2020 Jun;andr.12848.

7 Kayaaslan B, Korukluoglu G, Hasanoglu I, Kalem AK, Eser F, Akinci E, et al. Investigation of SARS-CoV-2 in semen of patients in the acute stage of COVID-19 infection. Urol Int. 2020;104(9-10):678-83.

8 Khalili MA, Leisegang K, Majzoub A, Finelli R, Panner Selvam MK, Henkel R, et al. Male Fertility and the COVID-19 Pandemic: Systematic Review of the Literature [Online ahead of print.]. World J Mens Health. 2020 Oct;38(4):506-20. 